\title{
$\widehat{A}$ Madridge \\ madridge Journal of Nursing \\ interconnecting S
}

Research Article

Open Access

\section{Breast Feeding and Bottle (formula) Feeding Habits among Omani Babies}

\author{
Al-Mamari TM, Al-Ghafri MS, Al-Wahaibi MS, Ambusaidi SA, and Hameed Swadi Hassan \\ School of Pharmacy, College of Pharmacy and Nursing, University of Nizwa
}

\section{Article Info}

\author{
*Corresponding author: \\ Hameed Swadi Hassan \\ Associate Professor \\ School of Pharmacy \\ College of Pharmacy and Nursing \\ University of Nizwa \\ Birkat Al-Mouz \\ Nizwa, Oman \\ E-mail: hameed@unizwa.edu.om
}

Received: August 30, 2017

Accepted: October 21, 2017

Published: October 27, 2017

Citation: Al-Mamari TM, Al-Ghafri MS, AlWahaibi MS, Ambusaidi SA, Hassan HS. Breast Feeding and Bottle (formula) Feeding Habits among Omani Babies. Madridge J Nurs. 2017; 2(2): 81-86.

doi: $10.18689 / \mathrm{mjn}-1000115$

Copyright: (c) 2017 The Author(s). This work is licensed under a Creative Commons Attribution 4.0 International License, which permits unrestricted use, distribution, and reproduction in any medium, provided the original work is properly cited.

Published by Madridge Publishers

\begin{abstract}
Choosing whether to breast feed or formula feed the baby is one of the first decisions expectant parents will make. Most health care professionals recommend breast feeding because it helps defend against infections, prevent allergies and protect against a number of chronic conditions. The aim of this study is to evaluate the breast feeding habit compared to formula feeding among Omani babies from the period of delivery to weaning and to highlight the various disadvantages of the formula feeding.

The required information was collected from designed questionnaires that include several variables and based on similar previously conducted studies in different parts of the world. All the participants (mothers) appeared to be of good general health and most of them are educated. 1200 questionnaires have been distributed to mothers in six different regions in Oman during 2013-2016. Mothers of both male and female babies were included and habits of either breast and/or formula feeding have been evaluated. The findings are illustrated in histograms using Microsoft Excel programs and the important, related, issues are discussed.

The results show that $42.7 \%$ were exclusively breast fed compared to $34.6 \%$ formula fed. However, $22.7 \%$ of babies were found to be a combination of breast and formula milk. The period of breast feeding was found to be extended over one year in $60.4 \%$ and the frequency of breast feeding was also seen to be more than 6 times a day in the majority of cases (61\%). The reasons behind breast feeding and formula feeding as well as the disadvantages of the formula feeding are illustrated in this study.
\end{abstract}

Keywords: Breast feeding; Formula feeding; Oman.

\section{Introduction}

The World Health Organization (WHO) and the American academy of Pediatrics (AAP) emphasize the value of breast feeding for mothers as well as children $[1,2]$. Both recommend exclusive breast feeding for the first 6 months of life. Breast feeding is particularly beneficial for premature babies and also may protect children against allergies, asthma, diabetes, obesity and sudden infant death syndrome [2,3].

Breast milk provides the ideal nutrition for babies, it contains perfect mixture of vitamins, protein, and fat that baby requires. Also, it contains antibodies and can help the baby resist infections [4]. The benefits of breast feeding for mothers and babies have been widely recognized and researched. Studies have shown that breast feeding is superior to baby formula feeding because of its protective properties against illness and nutritional advantages [5]. For the mother, it increases child spacing [6], reduce risk of ovarian and breast cancer [7,8], less postpartum bleeding and more rapid uterine involution [9], early pre-pregnant weight [10]. Enhances maternal-baby bonding, decrease maternal anxiety and enhance calmness and social responsiveness are also reported in this connection [11]. 
It is globally recommended that human milk is the best nutrition for babies, both for preterm and full term. Babies who are breastfed for 6 months experience less morbidity from gastrointestinal tract infection. No deficits have been demonstrated in growth among babies from either developing or developed countries who are exclusively breast fed for 6 months or longer. Thus WHO Assembly adopted a resolution to recommend exclusive breast feeding for 6 months to its member countries [12]. Despite the benefits of the breast feeding, UNICEF estimates that 1.5 million babies die across the globe as they do not get the required nutrients which are present in the mother's milk [13].

Oman is an Arab country with a total population, at present, of 4.7 million. Rapid improvements have been occurring in public health and in individual health status in the Sultanate of Oman as a result of the 5 year health development plans that have been implemented since 1976 [14]. In Oman breastfeeding is the primary mean of feeding newborns, however, according to a report of 2003 only $31 \%$ of the new born babies were exclusively breastfed for the first 6 months [15], while in 2006, the Child Health Register showed that $53.3 \%$ of children from the age of 5 months were fed with formula and other milk.

Lack of breastfeeding and breastfeeding initiatives are even prevalent in the developed countries such as the UK and the US [16]. According to a survey conducted between 19911994 by the National Health and Nutrition Examination Survey (NHANES) in the US, it was found that only $53 \%$ of babies are exclusively breastfed at birth and $22 \%$ of infants are being exclusively breastfed at 6 months [17]. In 2003, the initiation rate had increased to $71 \%$ (an $18 \%$ increase) but the duration by six months had decreased to $14 \%$ [18].

In the UK (1991-1992), it was found that only $69 \%$ of the babies are breastfed when they are born and the rate reduces to $52 \%$ when the baby is two weeks old. Only $21 \%$ of the mothers continue to breastfeed their children till the age of 6 months [16].

Child health programs in Oman are considered to be successful. Before 1970, baby mortality in the sultanate of Oman was estimated to be around 214 out of 1000 births, which later by 1992 reduced to 25 [18].

Issues pertaining to breast feeding are affected by various factors such as the living environment, maternal education, employment, workplace pressure, knowledge of benefits of breast feeding, milk ejection reflex, inverted nipples, insufficient milk production, and maternal /infant diseases [19]. It is observed that the insufficient knowledge among health care providers can also affect breast feeding practices. A large number of health care providers present information based on their own breast feeding practices rather than sufficiently proven knowledge of breast feeding [20].

A study in Latin America by Betran AP et. al., reported that since exclusive breast feeding remains uncommon in many countries, improving rates of exclusive breast feeding in early infancy would probably substantially reduce baby mortality worldwide [21].
Formula feeding is often seen as a safe, easy alternative to breast feeding, but there are risks [22]. However, breast milk cannot be duplicated by any other means [23]. Babies who are artificially fed are disadvantaged due to constituents of the substituent's and also by factors associated with their manufacture. Nutrients in artificial formula can be lacking, deficient or excessive. Cow milk protein is casein-dominant, and takes longer to digest. The fat is either butter fat or mixtures of vegetable oil with fatty acid composition very different from that of human milk. Infant formula also lacks antibodies, cholesterol, free amino acids, glucosamine, enzymes and other bioactive substances [22,24].

Failure to give mothers adequate encouragement and sufficient guidance about the importance of breast feeding and ways to overcome some problems that may be encountered can create some tension and anxiety which can hinder the production of their milk. Mother's inability to obtain compelling and well integrated information on the benefits of breast feeding and lack of encouragement can be the main reasons for cessation of exclusive breast feeding during the first 6 months. UNICEF believes that many of the factors influencing the premature termination of breast feeding could be solved or avoided with better support from health services [25].

As formula milk is used widely, there are so many issues encountered with such type of feeding including obesity, skin allergies, diarrhea or constipation $[21,26]$. There are many reasons why women decide to use formula milk. Formula milk is found to be easier and quicker. Either parent can feed the baby at any time.

Infectious and allergic diseases are common among bottle fed children. To reduce the incidence and severity of these diseases, preventive strategies and measures have often focused on the babies of breast feeding and feeding with bottle milk. The influence of breast feeding on induction of asthma and other allergic diseases in children appears contradictory. Some studies indicate that prolonged breast feeding significantly decreases the risk of asthma and other allergic diseases among children [27]. However, other studies have failed to confirm this or even suggest that breast feeding is associated with an increased risk for childhood asthma in the presence of maternal asthma [28]. Preventing the infectious and allergic diseases and their consequences may be an important argument to encourage breast feeding in the local society.

\section{Need of the study}

As a number of health organizations recommended breast feeding as an ideal choice for the babies, and because of the increase use of formula feeding nowadays due to many reasons, it was chosen to evaluate the breast feeding and formula feeding habits among mothers in different regions in Oman and to report the reasons behind both types of feeding. This study may, also, assist the health care providers to develop a range of activities to activate their role in encouraging breast feeding and making mothers aware of the disadvantages of formula feeding through the exploitation of health education and awareness to highlight the risks and the enormous problems arising from its use. 


\section{Material and Methods}

This is a prospective survey with the use of questionnaires to evaluate the breastfeeding and bottle feeding habits among Omani babies and to highlight the disadvantages of formula feeding. Six different regions (Willayat) were chosen as a sample in Oman. These regions include; Al-Mawaleh (Muscat), Nizwa, Izki, Manah (Al-Dakhylia), Sohar and Liwa (North AlBatina). The study was conducted during 2013 - 2016 by using self-administered questionnaires that included demographic parameters and questions about feeding their babies. Mothers and baby's demographic parameters were used in this study. The mother's parameters include mother's age, mother's occupation, employment and education. The baby demographic parameters include the baby gender and the baby age. Directly related questions concerning the type of feeding, period of breast feeding, frequency of breast feeding, onset of breast feeding, reasons behind breast feeding/or formula feeding, breast milk insufficiency and disadvantages of breast feeding were included in the questionnaire.

1200 mothers (200 mothers in each region) whose babies were either breast fed or formula fed and willing to participate and respond to the questionnaire were randomly selected. The questionnaires were based on similar questionnaires used in previous similar studies [29,30]. These questionnaires are translated to Arabic (the local language) and validated. The validity was established by checking in a small population of subjects. Few (10\%) uneducated women were assisted to answer the questionnaires. All the obtained data were analyzed and illustrated in histograms using Microsoft Excelprograms.

\section{Results}

Among the investigated mothers, the largest percentage (37\%) was in the age range from 26-30 years and most of them $(66 \%)$ were found to be employed in government and private sectors. Also, the vast majority (90\%) of the mothers were educated.

More female babies (56.6\%) were included in this study and the majority of babies of both genders (56.5) ranged from 1-2 years in age.

The type of feeding was reported to be of exclusive breast feeding in $42.7 \%$ of babies, whereas formula feeding was in $34.6 \%$. However, $22.7 \%$ of cases were found to be a combination of both breast and formula milk. The period of breast feeding was found to be extended over one year in the majority of cases (60.4\%) as appeared in figure 1.

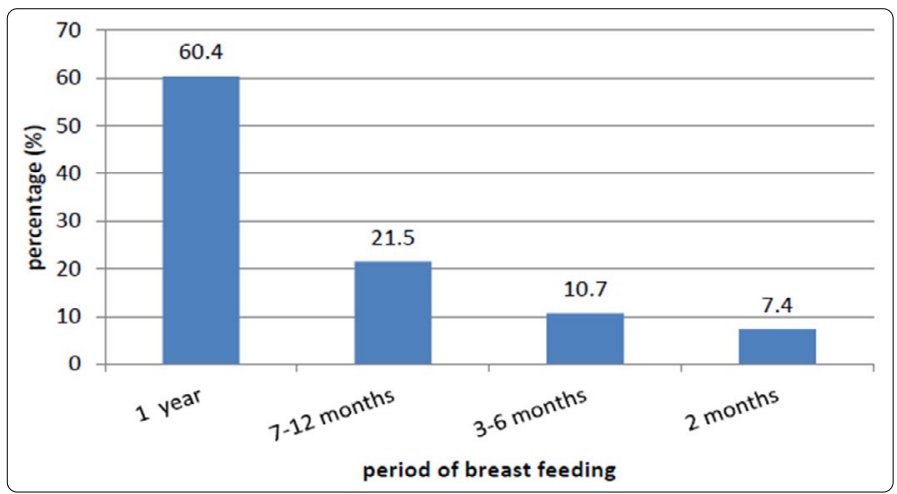

Figure 1. Period of breast feeding
The frequency of breast feeding among the investigated sample was seen to be more than 6 times/day in $61 \%$ of cases, 3-5 times/day in $41.3 \%$ of cases and only 2 times/day in $24 \%$ of cases. The onset of breast feeding, on the other hand, was noticed to be immediately after birth in $47 \%$ of babies and during the first 24 hours in the remaining $53 \%$ of babies (Figure 2).

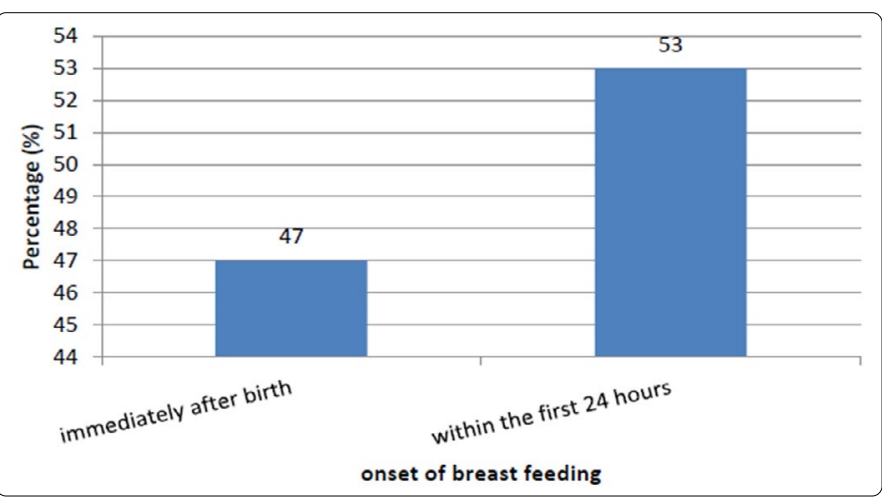

Figure 2. Onset of breast feeding

Regarding the opinion of the investigated mothers about the continuation of breast feeding after the babies have started solid food, it was noted that $89 \%$ of mothers will continue breast feeding their babies after they have started solid food.

Approaches to overcome breast milk insufficiency also reported in this study and the women's view is to drink more fluid (41\%) and to top up breast feeding with formula feeding after adequate breast feeding if the baby is still appearing hungry (39\%). Only $20 \%$ advised increase the frequency of breast feeding.

Concerning the perception of the investigated mothers about reasons (benefits) behind the breast feeding, it was found that $42 \%$ of the mothers noted that breast feeding is good for the baby's health because it provides the essential nutrients to the babies. $41.3 \%$ of the mothers stated that it strengthens the immunity of the babies. $7 \%$ of mothers reported it increases infant-mother bonding, cost free (5.7\%) and birth spacing (4\%) as appeared in figure 3.

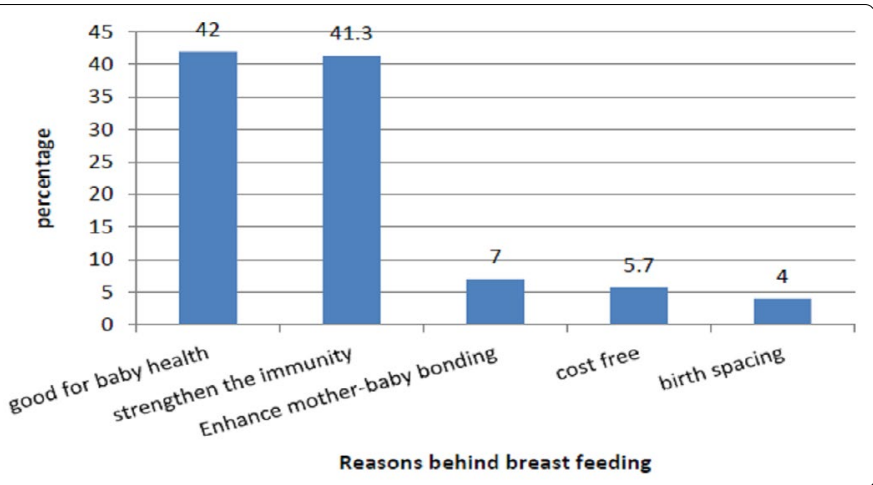

Figure 3. Perception of reasons behind breast feeding

Regarding the perception of mothers about reasons behind formula feeding, the highest percentage of mothers (45\%) reported that formula feeding is suitable for mothers who are employed. Good choice for mothers who lack breast milk (28\%), good for mothers with diseases and medications 
(12\%), easy and can be quickly prepared (8\%), and others can help (5\%). Very few cases (2\%), however, preferred formula feeding for social reasons (Figure 4).

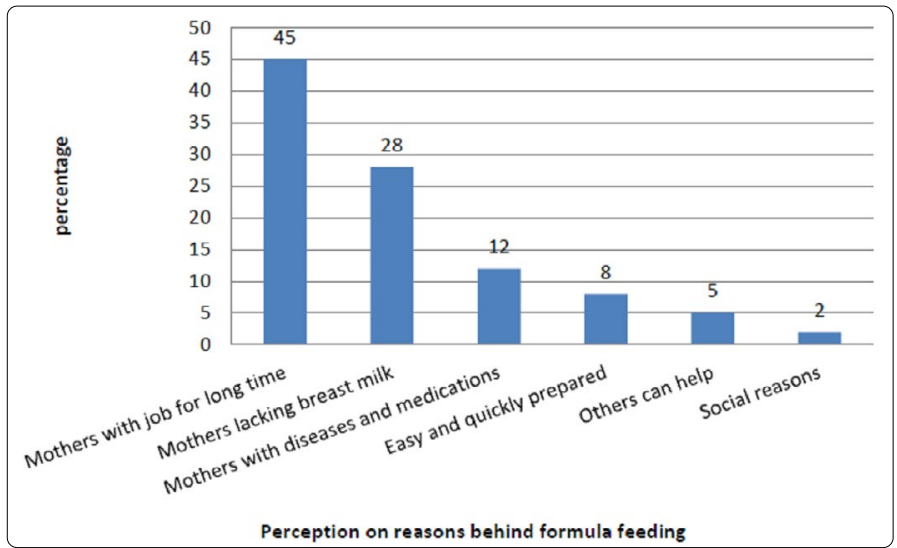

Figure 4. Perseption on the reasons behind formula feeding

In regard to disadvantages of formula feeding, 37\% of cases reported it weakened baby's immunity. $22 \%$ of cases noted it causes flatulence and other gastrointestinal problems and in $15 \%$ no adequate nutrients and vitamins are provided. In others (12\%), it causes obesity and skin rash. Some women (8\%) reported that they cannot keep the milk for long period of time and $6 \%$ of cases reported it is costly (Figure 5).

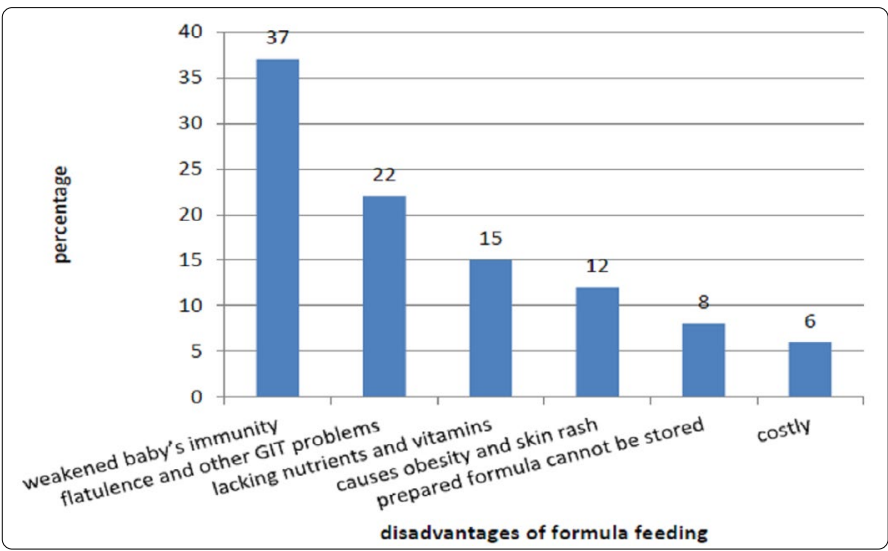

Figure 5. Dis advantages of formula feeding

\section{Discussion}

This is a prospective survey study conducted in order to evaluate the breast feeding and formula feeding habits among Omani babies from the period of delivery to weaning during the years of 2013-2016 and to highlight any disadvantages that might be associated with formula feeding. 1200 mothers randomly selected in six different regions (Willayat) in Oman in order to obtain the required information. All mothers investigated appeared to be of good general health and the majority were educated and employed (full time) in various government and private sectors.

Many factors play a great role in deciding whether exclusive breast feeding or exclusive formula feeding or both are of benefit to the babies ultimately the decision should be made by the parents [23]. In general, breast feeding is considered to be the best nutritional option for babies by the major medical organizations, but it is not right for every mother [31]. Breast feeding is chosen because of its convenience, nutritional values, ease of digestion, free of cost, obesity prevention and fighting infections $[4,5]$. Commercial formulas try to duplicate the ingredients in breast milk, but there are significant differences in the nutrient contents of these products [32]. Such advantages of breast milk have been met in the majority of cases in this study.

Factors that might encourage the mothers to breast feed include personal comfort, time and frequency of feeding, diet and maternal medical conditions [32]. In others, breast feeding has been reported to increase child spacing, enhance maternalinfant bonding, decrease maternal anxiety and enhance calmness and social responsiveness [22,25]. Formula feeding, on the other hand, can be easily prepared but it lacks the antibodies that are found in the breast milk, expensive and gas and constipation producing and in all cases it cannot match the complexity of breast milk. In addition, asthma, atopic dermatitis and allergic rhinitis are widely associated with formula feeding rather than breast feeding [33]. Some of these disorders are also reported by some women in this study.

In Oman breastfeeding is the primary mean of feeding, however, according to a report of 2003 only $31 \%$ of the babies were exclusively breastfed for the first 6 months [15], while in 2006, the Child Health Register showed that 53.3\% Of children from the age of 5 months were fed with formula and other milk. When compared to the results of this study, it is noticed that about $42.7 \%$ of babies were breastfed and the period of the exclusive breast feeding has extended to more than one year in the majority of babies i.e. $60.4 \%$ which reflects an overall achievements in the breast feeding and its duration than what is reported in 2003.

According to the social consensus among the states in the Gulf region, the initiation and duration of feeding problems are not confined to the Sultanate of Oman, but exists in all countries in the region [18].

In many developing countries, initiation of breast feeding is delayed by hours if not days, and about $44 \%$ of babies in the developing world are now being exclusively breastfed for their first four months [34]. In this study, the period of breast feeding appeared to be continued over one year in the majority of cases (60.4\%). This might be attributed to the role of education and the efforts of health care providers in this respect.

In the US [35], the duration of breast feeding fell far from the recommended guidelines. In 2005, $74.2 \%$ of US infants were breastfed at least once after delivery, but only $12.3 \%$ were exclusively breast fed at age of 6 months. In 2014, however, the rate increased to $82.5 \%$ of US children breastfed and the exclusive breast feeding at the age of six months appeared to be increased to $24.9 \%$. When compared to this study, it seems that $42.7 \%$ of Omani babies are on exclusive breast milk and the majority of babies (60.4\%) were fed over a period of one year. The frequency of feeding appeared to be more than 6 times a day in the majority of babies (61\%). This might be, again, attributed to the education and increase awareness of Omani mothers about the benefits of the breast feeding. 
In the US, several states have now integrated education on breast feeding into a variety of disciplines. The Centre for Disease and Control believes that breastfeeding can be effectively and appropriately involve the incorporation of breastfeeding into larger academic disciplines [36]. Recent projects in the UK as part of the baby feeding initiative has raised the serious need about breastfeeding among young students [37]. The projects faced challenges with teaching a subject which is often perceived as sexual in nature and "out of place" in a school curriculum [38]. The researcher has found that the favoured curriculum placement was PSHE (Personal Social \& Health Education). Teaching material was developed after consultation with students, teachers and health professional and included visual, experimental and interactive methods. Materials were displayed during Breastfeeding Awareness Week (BFAW), which is also an invaluable tool [38].

The perception of the investigated mothers in this study about the reasons behind using the formula milk is clearly stated by the women investigated in this study. It is used after adequate breast feeding if the baby is still appearing hungry and it is found suitable for mothers who work long hours. Others reported it is a good choice for mothers with diseases and medications, easy and can be quickly prepared, relatives can help. Few cases, however, reported social reasons behind choosing formula feeding.

So many disadvantages are reported for formula feeding and seem to be similar to previously reported cases [22].

Since the last three decades, Oman has taken several positive measures to improve women's and baby's health care and the authorities have begun to circulate and implement a program to support maternal and child care services at the national level in order to reduce the morbidity and mortality through the provision of health care for women during pregnancy, child birth and postnatal period [18]. It is hoped that this will draw attention to further improvement of infant feeding practices in the Sultanate of Oman.

\section{Conclusion}

Based on the obtained results, breast milk was reported by the mothers to be the best source of nutrition for the babies. It is considered good for baby health and development and strengthens the immune system of the baby to fight infection and enhance maternal-infant bonding. Despite the achievements which have increased the rate and duration of breastfeeding in Oman, the results are below the expectation and need to be further evaluated after introduction of several educational measures.

\section{Recommendations}

Encouraging women to feed their babies with breast milk if they are able to do so, being that breast milk is the natural nutritional source for babies less than one year of age. After other foods have been introduced, breast feeding should continue until the baby is at least one year old and so long after that as both mother and child willing. More efforts are needed and more education and social programs have to be advocated. The Omani Women Association in addition to other governmental and public authorities may, altogether, play a major role in community education.

Also, education about breastfeeding might be included in the school's programs and universities curricula to increase the community orientation. Further studies could be conducted to evaluate any additional factors which could influence the knowledge and practices among the Omani mothers.

\section{Acknowledgment}

We would like to express our thanks and gratitude to the University of Nizwa and the College of Pharmacy and Nursing for giving this opportunity to conduct this research via the provision of the academic programs. Our thanks are also extended to the respected participants without their kind participation this study cannot be conducted.

\section{References}

1. WHO. Exclusive breastfeeding.

2. American Academy of Pediatrics: Work group on breast feeding and the use of human milk. Pediatrics. 1997; 100(6): 1035-39.

3. Position of the American Dietic Association/breaking the barriers to breast feeding.JAmDietAssoc.2001;101(10):1213-20. doi:10.1016/j.jada.2005.03.015

4. Breastfeeding Benefits for Mom and baby-webMD.

5. Arora S, MucJunkin C, Wehrer J, Kuhn P. Major Factors Influencing Breastfeeding Rates: Mother's Perception of Father's Attitude and Milk Supply. Pediatrics. 2000; 106(5): 1-5.

6. Kennedy KI, Visness CM. Contraceptive efficacy of lactational amenorrhoea. Lancet. 1992; 339: 227-30.

7. Rosenblatt KA, Thomas DB. WHO Collaborative Study of Neoplasia and Steroid Contraceptives. Lactation and the risk of ovarian cancer. Int J Epidemiol. 1993; 22: 192-197.

8. Newcomb PA, Storer BE, Longnecker MP, et al. Lactation and a reduced risk of premenopausal breast cancer. N Engl J Med. 1994; 330: 81-7. doi: 10.1056/NEJM199401133300201

9. Chua $S$, Arulkumaran $S$, Lim I, et al. Influence of breastfeeding and nipple stimulation on postpartum uterine activity. Br J Obstet Gynaecol. 1994; 101: 804-805. doi: 10.1111/j.1471-0528.1994.tb11950.x

10. Dewey KG, Heinig MJ, Nommsen LA. Maternal weight-loss patterns during prolonged lactation. Am J Clin Nutr. 1993; 58: 162-66.

11. Breastfeeding vs Bottlefeeding: American Pregnancy Association. The benefits of breastfeeding, 2015.

12. Kramer MS, Kakuma R. The optimal Duration of Exclusive breastfeeding. A systematic review. Department of Nutrition for Health and Development. World Health Organization, Geneva; 2001.

13. NHS. Breastfeeding NHS, 2005.

14. Sulaiman AJ, Al-Riyami A, Farid S, Ebrahim GJ. Oman Family Health Survey 1995. J Trop Pediatr. 2001; 47(Suppl 1): 1-33.

15. UNICEF. Situation of children in the world, 2003.

16. Hamlyn B, Brooker S, Oleinikova K, Wands S. Infant feeding. The stationary office, London: 2002.

17. Li R, Ogden C, Ballew C, Gillespie C, Crummer-Strawn L. Prevalence of exclusive breastfeeding among US infants: The Third National Health and Nutrition Examination Survey (Phase 11, 1991-1994). Am J Public Health. 2002; 92 (7): 1107-10. 
18. Al-Sinani M. Breastfeeding in Oman-The way forward. Oman Medical Journal. 2008; 23 (4): 236-40.

19. Fleischer MK, Weaver L, Branca F, Robertson A. Feeding and nutrition of infants and young children: Guidelines for the WHO European Region, with emphasis on the former Soviet countries. WHO Regional Publications, European Series. No. 87. WHO; 2003.

20. Sears M, Sears W. The Breastfeeding book: Everything You Need to Know about Nursing Your Child from Birth Through Weaning. United States: Little, Brown company; 2000.

21. Betran $A P$, de Onis $M$, Lauer JA, Villar J. Ecological study of effect of breastfeeding on infant mortality in Latin America. BMJ. 2001; 323(7308): 303.

22. Pairman, S. Pincombe J, Thorogood C, Tracy S. Review of Midwifery: Elsevier, Sydney, 2006.

23. Breast feeding vs Formula feeding. August 2017

24. Davidson MC, London ML, Ladewing PW. Olds' Maternal-Newborn Nursing \& Women's Health Across the life span; $10^{\text {th }}$ ed. New York: Pearson; 2015.

25. Auerbach KG. Employed breastfeeding mothers; problems they encounter. Birth. 1984; 11 (1): 17-20. doi: 10.1111/j.1523-536X.1984.tb00736.x

26. Guss E. Maternal embloyment and breastfeeding. A study of 567 women's experience. Am J Dis Child. 1984; 138(10): 958-60.

27. Wjst M, Dold S, Reitmeier P, Wulff A, Nicoli T, Von Mutius E. Does breast feeding prevent asthma and allergies? Results of the Munich asthma and allergy study. Monatschrkinderheilk. 1992; 140: 769-74.

28. Wrigh AL, Holberg CJ, Taussig LM, Martinez FD. Factors influencing the relation of infant feeding to asthma and recurrent wheeze in childhood. Thorax. 2001; 56 (3): 192-7.
29. Breastfeeding/bottle feeding questionnaire- I have sought permission from baby centre moderators. Community Baby Centre. Mar 14, 2011.

30. Tanash H. Breastfeeding knowledge, practice, attitudes, and influencing factors. Findings from selected sample of breast feeding mothers in Bemidji, Minnesota, 2014.

31. http://kids health.Org/parent/growth/feeding/breast bottle feeding/ html/Accessed 21 Nov. 2015.

32. How often should I breastfeed. American Academy: The Nemours Foundation; 1995.

33. Perinat J. Current research Continues to support Breastfeeding Benefits. Lamaze International; 2001 (Accessed August 2017).

34. UNICEF. Health Bill: Report Stage Briefing. 2006

35. Centers for Disease Control and Prevention. Breastfeeding among US children born 2000-2014. CDC National Immunization Survey.

36. Shealy KR, Li R, Benton-Davis S, Grummer-Strawn LM. The CDC Guide to Breastfeeding Interventions. Atlanta: US Department of Health and Human Services, Center for Disease Control and Prevention, 2005.

37. Dykes F. (2003) Infant Feeding Initiative: A Report Evaluating the Breastfeeding Practice Projects 1999-2002.

38. Dyson L, Renfrew M, McFadden A, McCormick F, Herbert G, Thomas J. Effective action briefing on the initiation and duration of breastfeeding Effective action recommendations. National Institute for Health and Clinical Excellence, 2006. 